\title{
Expression profiling of genes in rheumatoid fibroblast-like synoviocytes regulated by Fas ligand via cDNA microarray analysis
}

\author{
KOJI FUKUDA ${ }^{1}$, YASUSHI MIURA ${ }^{1,2}$, TOSHIHISA MAEDA ${ }^{1}$, SHINYA HAYASHI $^{1}$, \\ TOMOYUKI MATSUMOTO $^{1}$ and RYOSUKE KURODA ${ }^{1}$
}

\author{
${ }^{1}$ Department of Orthopaedic Surgery, Kobe University Graduate School of Medicine, Kobe, Hyogo 650-0017; \\ ${ }^{2}$ Division of Orthopedic Science, Department of Rehabilitation Science, Kobe University Graduate School of \\ Health Science, Kobe, Hyogo 654-0142, Japan
}

Received July 12, 2020; Accepted June 25, 2021

DOI: $10.3892 /$ etm.2021.10432

\begin{abstract}
Rheumatoid arthritis (RA) is an autoimmune disease that causes chronic inflammation in synovial tissues. Hyperplasia of synovial tissues leads to the formation of pannus that invades the joint cartilage and bone, resulting in joint destruction. Fas ligand (FasL), which is a member of the tumor necrosis factor superfamily, contributes to the pathogenesis of autoimmune diseases, including RA. The current study attempted to identify genes whose expressions in rheumatoid fibroblast-like synoviocytes (RA-FLS) were regulated by FasL, using cDNA microarray. A total of four individual lines of primary cultured RA-FLS were incubated either with recombinant human FasL protein or PBS as an unstimulated control for $12 \mathrm{~h}$. Gene expression was detected using a microarray assay. The results revealed the expression profiles of genes in RA-FLS regulated by Fas and investigated the functions of the genes that were regulated. Among the genes in this profile, the mRNA expression changes of the following genes were indicated to be of note using RT-qPCR: Dual specificity phosphatase 6, epiregulin, interleukin 11, angiopoietin-like 7, protein inhibitor of activated STAT 2 and growth differentiation factor 5 . These genes may affect the pathogenesis of RA by affecting apoptosis, proliferation, cytokine production, cytokine-induced inflammation, intracellular signaling, angiogenesis, bone destruction and chondrogenesis. To the best of our knowledge, the current study is the first study to reveal the expression profile of genes in RA-FLS regulated by FasL. The data demonstrated that
\end{abstract}

Correspondence to: Dr Yasushi Miura, Division of Orthopedic Science, Department of Rehabilitation Science, Kobe University Graduate School of Health Science, 7-10-2 Tomogaoka, Kobe, Hyogo 654-0142, Japan

E-mail: miura@kobe-u.ac.jp

Key words: rheumatoid arthritis, fibroblast-like synoviocytes, Fas ligand, decoy receptor 3 , microarray assay, gene expression profile
FasL may regulate the expression of a number of key molecules in RA-FLS, thus affecting RA pathogenesis. Further studies of the genes detected may improve the understanding of RA pathogenesis and provide novel treatment targets for RA.

\section{Introduction}

Rheumatoid arthritis (RA) is an autoimmune disease that causes chronic inflammation in synovial tissues. Hyperplasia of synovial tissues leads to the formation of pannus, which invades joint cartilage and bone, resulting in joint destruction. Previous reports have indicated that a number of features of transformed long-lived cells are observed in hyperplastic synovial tissues of patients with RA, such as oncogene expression, resistance to apoptosis, and the presence of somatic mutations (1-3). Several explanations for resistance to apoptosis of rheumatoid fibroblast-like synoviocytes (RA-FLS) have been proposed, including deregulation of the Bcl-2 family of proteins critical to the intrinsic apoptosis pathway, deregulation of NF- $\mathrm{B}$ signaling, p53 mutations, and low expression of PUMA; these are all found in RA synovium and FLS, which provides an explanation for the lack of p53-induced FLS apoptosis (4). In addition, it has been reported that hyperproliferation of RA synovial cells involves the abnormal function of death receptors such as Fas and death receptor $3(5,6)$.

Fas ligand (FasL)/TNFSF6, a member of the tumor necrosis factor (TNF) superfamily, is expressed by various cell types in arthritic synovium, including $\mathrm{T}$ cells, synovial fibroblasts, and macrophages (7), and can promote apoptosis in activated primary $\mathrm{B}$ cells, $\mathrm{T}$ cells, dendritic cells, and synovial fibroblasts through Fas $(8,9)$. Inhibition of the Fas/FasL pathway contributes to synovial hyperplasia of RA (10-12). Apoptosis through the Fas/FasL pathway in RA synovial cells is inhibited by pro-inflammatory cytokines present within the synovium (8). Meanwhile, the Fas/FasL system may have a pro-inflammatory effect in RA $(13,14)$. Audo et al demonstrated that membrane-bound FasL induces apoptosis as well as proliferation, whereas soluble FasL stimulates only proliferation (13). Moreover, soluble FasL activates 
several signaling pathways in RA-FLS, such as extracellular signal-regulated kinase (ERK)-1/2, phosphatidyl-inositol 3kinase, caspase 8, and c-jun N-terminal kinase (13). However, the mechanisms and cell targets for these effects are still poorly understood.

Decoy receptor 3 (DcR3)/TR6/M68/TNFRSF6b, a member of the TNF receptor superfamily, binds to 3 ligands belonging to the TNF superfamily: FasL, LIGHT, and TL1A (15). Overexpression of DcR3 may benefit tumors by helping them avoid the cytotoxic and regulatory effects of FasL $(16,17)$, LIGHT (18), and TL1A (19). In our previous studies, we demonstrated that DcR3 overexpressed in RA-FLS and stimulated by TNF $\alpha$ protects cells from Fas-induced apoptosis (20). We previously also reported that DcR 3 could play a role as a ligand by binding to membrane-bound TL1A in the pathogenesis of RA (21-24).

Furthermore, the expression profiles of genes regulated by DcR3 and TL1A in RA-FLS have been revealed by the use of cDNA microarrays in our previous studies $(25,26)$, suggesting that signaling through DcR3 and its ligands is involved in the pathogenesis of RA. However, the contribution of FasL, another ligand of DcR3, to the pathogenesis of RA remains to be fully elucidated.

In the current study, we searched for genes whose expressions in RA-FLS were regulated by FasL using a cDNA microarray. The gene expression profiles revealed a series of genes that may play a significant role in the pathogenesis of RA via the FasL-Fas signaling pathway. Further study is needed to reveal the difference of the gene expression profiles among the ligands, which might result in better understanding the role of the FasL/TL1A/DcR3 signaling system in the pathogenesis of RA.

\section{Materials and methods}

Isolation and culture of synovial fibroblasts. RA-FLS were obtained from ten patients (samples 1-10) with RA who fulfilled the 1987 criteria of the American College of Rheumatology (formerly, the American Rheumatism Association) (27) during total knee replacement surgery from September 2014 to April 2019. Patients included one male and nine females aged $70.4 \pm 8.5$ years old. Their C-reactive protein levels and erythrocyte sedimentation rates were $1.4 \pm 2.6 \mathrm{mg} / \mathrm{dl}$ and $25.6 \pm 14.0 \mathrm{~mm} / \mathrm{h}$, respectively. As for the drug therapy for RA, five patients were administered oral methotrexate (MTX) (average MTX dose, 8.8 $\pm 4.6 \mathrm{mg} /$ week), two were administered tacrolimus $(1.5 \pm 0.5 \mathrm{~g} / \mathrm{day})$, two were administered salazosulfapyridine $(1.0 \pm 0.0 \mathrm{~g} / \mathrm{day})$, and two were administered bucillamine $(150.0 \pm 50.0 \mathrm{mg} / \mathrm{day})$. Prednisolone (PSL) was used to treat three patients (average PSL dose, $4.7 \pm 0.6 \mathrm{mg} /$ day). None of the patients had been treated with biological disease-modifying anti-rheumatic drugs (bioDMARDs) or Janus kinase inhibitors.

Synovial samples were collected from the patients, all of whom provided informed written consent to participate in this study in accordance with the World Medical Association Declaration of Helsinki Ethical Principles for Medical Research Involving Human Subjects. The protocol, including consent procedures, was approved by the Kobe University Graduate School of Health Sciences Ethics Committee (approval no. 308). Tissue specimens were minced and digested in Dulbecco's modified Eagle's medium (DMEM; Merck KGaA) containing $0.2 \%$ collagenase (Merck KGaA) for $2 \mathrm{~h}$ at $37^{\circ} \mathrm{C}$ with $5 \% \mathrm{CO}_{2}$. Dissociated cells were cultured in DMEM supplemented with $10 \%$ fetal bovine serum (Merck $\mathrm{KGaA}$ ) and $100 \mathrm{U} / \mathrm{ml}$ of penicillin/streptomycin (Meiji Seika Pharma Co., Ltd.). Following incubation overnight and the removal of non-adherent cells, adherent cells were further incubated in fresh medium. All experiments were conducted using cells from passages 3 to 4 (20).

Gene expression profiling. Four individual cell lines (samples $1-4)$ of primary cultured RA-FLS $\left(2 \times 10^{6}\right.$ cells/well) were incubated with $1,000 \mathrm{ng} / \mathrm{ml}$ of recombinant human FasL protein (R\&D Systems) or were left untreated with OPTI-MEM medium (Thermo Fisher Scientific, Inc.) as control for $12 \mathrm{~h}$ at $37^{\circ} \mathrm{C}$ with $5 \% \mathrm{CO}_{2}$. The concentration of FasL was determined by a preliminary experiment based of the previous reports using FasL $(28,29)$. After incubation, RNA was extracted with QIAshredder (Qiagen $\mathrm{GmbH}$ ) and an RNeasy Mini kit (Qiagen $\mathrm{GmbH}$ ) according to the manufacturer's protocol. Extraction of total RNA was performed for each sample separately.

Gene expressions were detected by a microarray assay (Human Genome U133 Plus 2.0, GeneChip ${ }^{\circledR}$ 3' Expression Array; Thermo Fisher Scientific, Inc.). The labeling of RNA probes, hybridization, and washing were carried out according to the manufacturer's protocol.

$R T$-qPCR analysis for $m R N A$ expression of genes regulated by FasL. RA-FLS (samples 5-10) were cultured in six-well plates at a density of $2 \times 10^{6}$ cells/well with $1,000 \mathrm{ng} / \mathrm{ml}$ of FasL or serum-free medium only as a control. RNA was extracted using the QIAshredder and RNeasy mini kits according to the manufacturer's protocols. Oligo (dT)-primed first-strand complementary DNA (cDNA) was synthesized ( $2 \mu \mathrm{g}$ total RNA) using a High Capacity cDNA Transcription kit (Applied Biosystems; Thermo Fisher Scientific). Relative expression levels of mRNA encoding DUSP6, EREG, IL-11, ANGPTL7, PIAS2, and GDF5 were compared using TaqMan ${ }^{\circledR}$ real-time PCR on a StepOne ${ }^{\text {TM }}$ real-time PCR system (Applied Biosystems; Thermo Fisher Scientific, Inc.). Pre-designed primers and probes for DUSP6 (Hs04329643 s1), EREG (Hs00914313_m1), IL-11 (Hs01055413_g1), ANGPTL7 (Hs00221727_m1), PIAS2 (Hs00915227_m1), GDF5 (Hs00167060_m1), and glyceraldehyde-3-phosphate dehydrogenase (GAPDH; Hs99999905_m1) were obtained from Applied Biosystems (Thermo Fisher Scientific, Inc.). Comparative analysis of each of these genes in individual patients was performed using StepOne ${ }^{\mathrm{TM}} 2.1$ software (Applied Biosystems; Thermo Fisher Scientific, Inc.) according to the manufacturer's protocol. All amplifications were conducted in duplicate. The mRNA expression levels of each gene were calculated using the comparative threshold cycle $(\Delta \Delta \mathrm{Cq})$ method as previously described (30).

Statistical analysis. Values are expressed as the mean \pm standard deviation unless otherwise indicated. As for the data analysis of the microarray assay, Avadis 3.3 Prophetic software (Strand Life Sciences) was used for statistical analysis (31). 
Table I. The 20 genes most upregulated by FasL. P-values were detected by a paired t-test.

\begin{tabular}{|c|c|c|c|}
\hline Gene abbreviation & P-value & $\mathrm{FC}(\mathrm{abs})$ & Gene name \\
\hline DUSP6 & 0.000018 & 34.61 & Dual specificity phosphatase 6 \\
\hline EREG & 0.019622 & 29.23 & Epiregulin \\
\hline IL-11 & 0.007275 & 25.28 & Interleukin 11 \\
\hline ANGPTL4 & 0.002853 & 23.50 & Angiopoietin-like 4 \\
\hline SLCO4A1 & 0.002094 & 20.39 & Solute carrier organic anion transporter family, member 4A1 \\
\hline TNFSF11 & 0.006236 & 18.48 & Tumor necrosis factor (ligand) superfamily, member 11 \\
\hline BDKRB1 & 0.000004 & 14.39 & Bradykinin receptor $\mathrm{B} 1$ \\
\hline $\begin{array}{l}\text { OTTHUMG00000172357// } \\
\text { RP11-475A13.2 }\end{array}$ & 0.000002 & 14.12 & NULL//NULL \\
\hline AREG//AREGB & 0.030537 & 13.77 & Amphiregulin//amphiregulin B \\
\hline LIF & 0.000498 & 13.53 & Leukemia inhibitory factor \\
\hline IFNA8 & 0.000039 & 12.09 & Interferon, $\alpha 8$ \\
\hline $\begin{array}{l}\text { OTTHUMG00000175763// } \\
\text { RP11-744D14.2 }\end{array}$ & 0.000716 & 11.73 & NULL//NULL \\
\hline HBEGF & 0.014773 & 11.34 & Heparin-binding EGF-like growth factor \\
\hline PPP4R4 & 0.023739 & 11.03 & Protein phosphatase 4 , regulatory subunit 4 \\
\hline NDP & 0.008832 & 10.67 & Norrie disease (pseudoglioma) \\
\hline NR4A3 & 0.000432 & 10.59 & Nuclear receptor subfamily 4 , group A, member 3 \\
\hline EGLN3 & 0.028458 & 9.95 & Egl nine homolog 3 (C. elegans) \\
\hline BMP2 & 0.000082 & 9.92 & Bone morphogenetic protein 2 \\
\hline UBR2 & 0.007847 & 9.91 & Ubiquitin protein ligase $\mathrm{E} 3$ component n-recognin 2 \\
\hline SLC38A10 & 0.001400 & 9.34 & Solute carrier family 38 , member 10 \\
\hline
\end{tabular}

FasL, Fas ligand.

Differentially expressed genes were extracted by a paired t-test, with $\mathrm{P}$ values $<0.05$ considered to indicate statistical significance and fold-change $>2.0$, and ordered into hierarchical clusters using the Euclidean algorithm as the distance measure and the complete algorithm as the linkage method.

The data analysis of the RT-qPCR assay was as follows. The Wilcoxon signed ranked test was used to evaluate the differences between mRNA expression levels of genes in the control group and FasL-stimulated group. Statistical analyses were conducted using Statcel (version 3; OMS Publishing, Inc.). $\mathrm{P}<0.05$ was considered to indicate a statistically significant difference.

\section{Results}

Microarray analysis (gene expression profiling of RA-FLS stimulated by FasL). The microarray analysis used in the current study (Human Genome U133 Plus 2.0, GeneChip ${ }^{\circledR}$ 3' Expression Array) was able to detect the expression of 27,420 genes.

The microarray analysis revealed that FasL upregulates or downregulates the expressions of various genes in RA-FLS. We used the NCBI's UniGene database (https:/www.ncbi.nlm. nih.gov/UniGene/clust.cgi?ORG=Hs\&CID=55682) to identify the genes. Among the 1039 genes differentially upregulated by FasL, 806 were annotated in the database. Twenty of the 806 genes upregulated by FasL are shown in Table I. Gene annotations of 1190 among the 1518 genes differentially downregulated by FasL were also in the database. Twenty of the 1190 downregulated genes by FasL are shown in Table II. Hierarchical clustering analysis was performed for genes for which expression changes were detected in at least 2 of the 4 samples, which was 247 genes. The results of hierarchical clustering analysis for these 247 genes are illustrated in Fig. 1.

Functional annotation. The 246 genes regulated by FasL were classified into categories registered in the David Bioinformatics Database (https://david.ncifcrf.gov/) according to their biological functions. The most significant 10 functional categories were as follows: Transcriptional activator activity, positive regulation of metabolic process, positive regulation of cellular metabolic process, positive regulation of macromolecule metabolic process, positive regulation of nitrogen compound metabolic process, regulation of phosphorylation, positive regulation of biological process, regulation of phosphate metabolic process, regulation of MAPK cascade, regulation of multicellular organismal process (Table III).

$m R N A$ expression detected by $R T-q P C R$. Based on the microarray assay, we confirmed the mRNA expressions of genes by real-time PCR. Fig. 2 shows the mRNA expression levels of the 3 most upregulated genes. DUSP6 was upregulated 21 times by FasL compared to the control, EREG was upregulated 24 times by FasL compared to the control, and 
Table II. The 20 genes most downregulated by FasL. P-values were detected by a paired t-test.

\begin{tabular}{|c|c|c|c|}
\hline Gene abbreviation & P-value & $\mathrm{FC}(\mathrm{abs})$ & Gene name \\
\hline ANGPTL7 & 0.000283 & 11.61 & Angiopoietin-like 7 \\
\hline PIAS2 & 0.001099 & 11.34 & Protein inhibitor of activated STAT, 2 \\
\hline LINC00310 & 0.000038 & 11.30 & Long intergenic non-protein coding RNA 310 \\
\hline GDF5 & 0.004260 & 11.12 & Growth differentiation factor 5 \\
\hline TBX22 & 0.000755 & 11.11 & T-box 22 \\
\hline DCAF4L1 & 0.000734 & 10.64 & DDB1 and CUL4 associated factor 4-like 1 \\
\hline KRT16 & 0.013331 & 10.62 & Keratin 16 \\
\hline $\begin{array}{l}\text { OTTHUMG00000180314// } \\
\text { RP1-193H18.2 }\end{array}$ & 0.003726 & 10.31 & NULL//NULL \\
\hline TAS2R40 & 0.000202 & 10.14 & Taste receptor, type 2 , member 40 \\
\hline HEPACAM2 & 0.001656 & 9.93 & HEPACAM family member 2 \\
\hline CSMD1 & 0.000096 & 9.87 & CUB and Sushi multiple domains 1 \\
\hline IQCA1 & 0.009692 & 9.63 & IQ motif containing with AAA domain 1 \\
\hline $\begin{array}{l}\text { LOC } 100996810 / / \\
\text { LOC } 283861\end{array}$ & 0.003182 & 9.26 & $\begin{array}{l}\text { Uncharacterized LOC100996810// } \\
\text { uncharacterized LOC283861 }\end{array}$ \\
\hline FGFR2 & 0.029699 & 9.25 & Fibroblast growth factor receptor 2 \\
\hline WDR65 & 0.000045 & 9.21 & WD repeat domain 65 \\
\hline LOC253573 & 0.001556 & 9.18 & Uncharacterized LOC253573 \\
\hline PHLDB2 & 0.001030 & 9.06 & Pleckstrin homology-like domain, family B, member 2 \\
\hline PCDHAC2 & 0.017711 & 9.01 & Protocadherin alpha subfamily C, 2 \\
\hline LOC 100506629 & 0.002936 & 8.72 & Uncharacterized LOC100506629 \\
\hline FAM66C & 0.003647 & 8.68 & Family with sequence similarity 66 , member $\mathrm{C}$ \\
\hline
\end{tabular}

FasL, Fas ligand.

IL-11 was upregulated 9 times by FasL compared to the control. Fig. 3 shows the mRNA expression levels of the 3 most downregulated genes. ANGPTL7 was downregulated 0.15 times by FasL compared to the control, PIAS2 was downregulated 0.58 times by FasL compared to the control, and GDF5 was downregulated 0.11 times by FasL compared to the control.

\section{Discussion}

Genome-wide gene expression cDNA microarrays provide a powerful technique to investigate the pathophysiology of a variety of diseases, including tumors (32-34),immune-mediated diseases $(35,36)$, and inflammatory diseases (37-39). Using microarray assays, we previously revealed the expression profiles of genes in RA-FLS regulated by DcR3 (25) and TL1A (26). Subsequently, based on the profile regulated by DcR3, we investigated the significance of IL-12B p40 (22), tryptophan hydroxylase 1 (24), and centrosomal protein $70 \mathrm{kDa}$ (23) as regulated by DcR3 in RA-FLS in detail. The profile regulated by TL1A included the following noteworthy genes: Spectrin repeat-containing nuclear envelope $1, \mathrm{Fc}$ receptor-like 2, PYD (pyrin domain)-containing 1, cell division cycle 45 homolog, signal transducer and activator of transcription 5B, and interferon regulatory factor 4 (26).

To the best of our knowledge, this is the first study to reveal the expression profiles of genes in RA-FLS regulated by FasL. Among the genes in this profile, the following genes were of note: Dual specificity phosphatase 6 (DUSP6), epiregulin (EREG), interleukin 11 (IL-11), angiopoietin-like 7 (ANGPTL7), protein inhibitor of activated STAT 2 (PIAS2), and growth differentiation factor 5 (GDF5); these genes were all highly regulated by FasL.

DUSP6 regulates $\mathrm{CD}^{+}{ }^{+} \mathrm{T}$-cell activation and differentiation by inhibiting $\mathrm{T}$-cell receptor dependent ERK 1/2 activation (40). It has been reported that DUSP6 promotes endothelial inflammation through the inducible expression of TNF- $\alpha$-induced intercellular adhesion molecule-1 via nuclear factor $\kappa \mathrm{B}$, which is independent of ERK signaling (41).

Epiregulin is a growth regulator that belongs to the epidermal growth factor (EGF) family and mediates the dose-dependent increase in proliferation of primary mouse keratinocytes (42). EREG is increased in patients with RA and is associated with the development of IL-6 amplifier activation (43). EREG triggers the temporal regulation of growth factors such as amphiregulin, betacellulin, transforming growth factor (TGF)- $\alpha$, fibroblast growth factor 2, placental growth factor 2 , and tenascin $\mathrm{C}$, contributing to the early phase of inflammation; each growth factor reciprocally regulates EREG in affected tissue during the late phase of inflammatory disease development (44). Secretion of vascular endothelial growth factor-A and EREG from RA-FLS was inhibited upon treatment with the aryl hydrocarbon receptor 

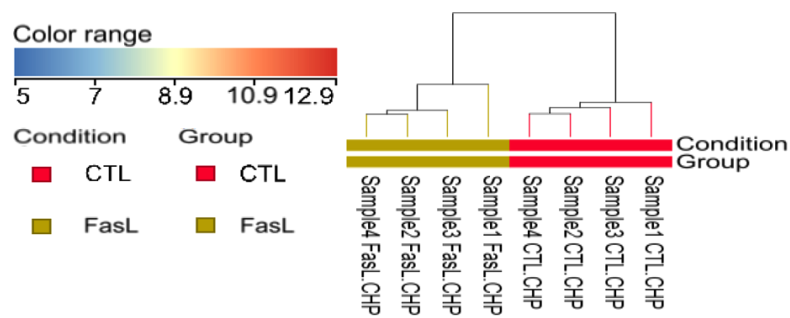

MEOX1

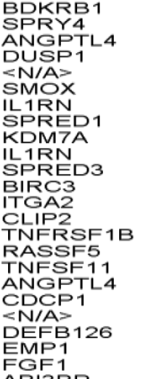

FGF 1
ABI3BP

INMA

AMEP3

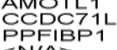

ANAAA

集NAA

NIM1K-AS2

MPDE

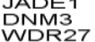

TBX18

PUS 240

CNAAB 344

CREBsL4

N

PLCE1

SHADTA

TLLLI 14

ACP6 100049716

$\mathrm{COC1000497}$
$\mathrm{CODC} 113$

NN/A>

DNM3O

TRIM59

GDF5

IL $21 \mathrm{R}$

SESN3

LOC100507557

ARHGA

KIF 100288911

LNFTO4

S $1-124 K 5.4$

CHD2 24156

STIA

RHEB

TMEM56

RFPL1
LOC101926967

LOC101

MAP $2 K 6$

KIF26B

STO 2
MAP $2 \mathrm{~K} 6$

L21R

AM133A

LOC257152

LGALS8-AS1

KN/A

FUT8-AS1

LOC101929112

RAB3O

RUNX1T1
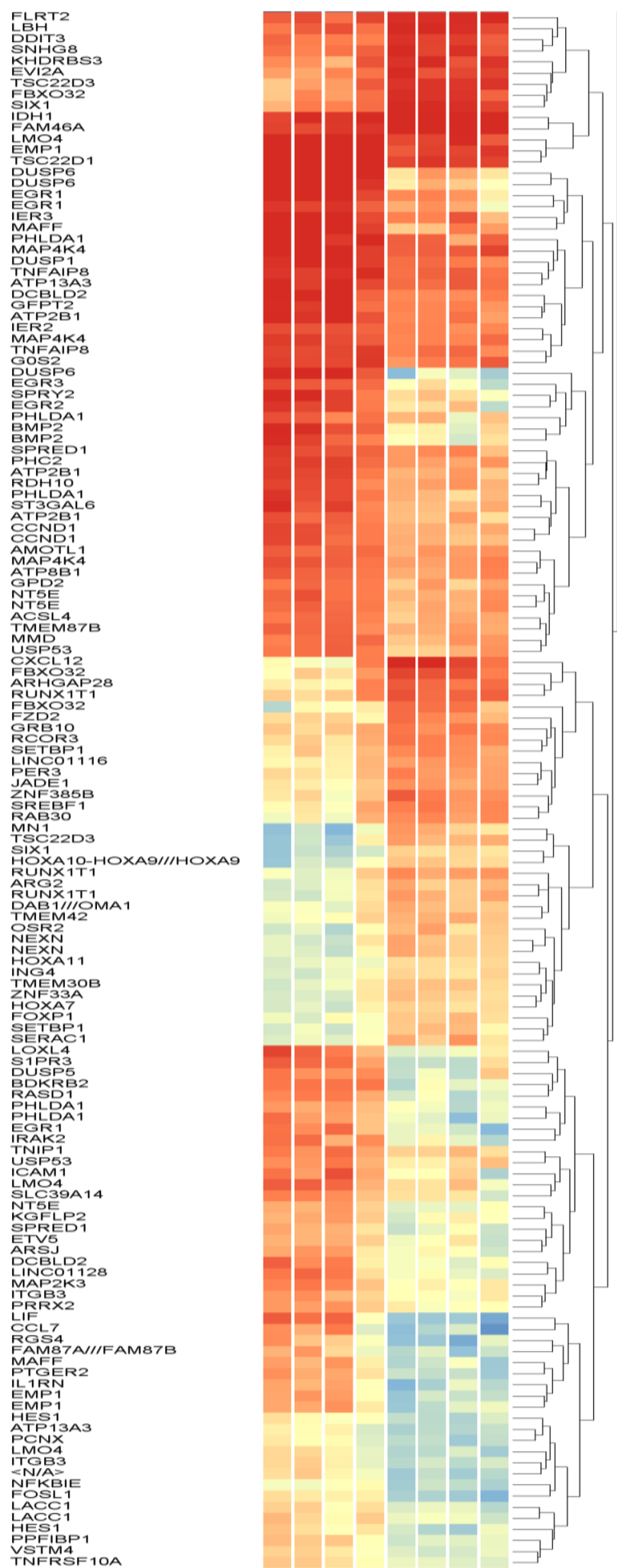

Figure 1. Heat map showing the result of hierarchical clustering. The heat map illustrates the expression values mapped to a color gradient from low (blue) to high expression (red). The horizontal dendrogram illustrates the similarity of functions between neighboring genes. The vertical dendrogram shows similarities in gene expression between neighboring samples.

antagonist GNF351, resulting in attenuation of RA-FLS cell migration, along with cytokine-induced RA-FLS cell proliferation (45).

IL-11 signaling appears to be initiated by the binding of IL-11 to IL-11 receptor $\alpha$ chain (IL-11R $\alpha$ ), which then binds gp130, the signaling unit of the IL- 6 cytokine family (46). IL-11 attenuates the inflammatory response through downregulation of proinflammatory cytokine release and nitric oxide production $(47,48)$. IL-11 contributes to RA angiogenesis directly and indirectly. IL-11 promotes endothelial cell migration and tube 
Table III. The 10 most significant functional categories of the 246 genes most differentially expressed by FasL exposure in RA-FLS. P-values were detected by a paired t-test.

\begin{tabular}{llc} 
GO Accession & \multicolumn{1}{c}{ GO Term } & Corrected P-value \\
\hline GO:0001228 & $\begin{array}{l}\text { Transcriptional activator activity, RNA polymerase II transcription } \\
\text { Regulatory region sequence-specific DNA binding }\end{array}$ & 0.000028 \\
GO:0009893| GO:0044253 & Positive regulation of metabolic process & 0.000028 \\
GO:0031325 & Positive regulation of cellular metabolic process & 0.000028 \\
GO:0010604 & Positive regulation of macromolecule metabolic process & 0.000028 \\
GO:0051173 & Positive regulation of nitrogen compound metabolic process & 0.000028 \\
GO:0042325 & Regulation of phosphorylation & 0.000066 \\
GO:0048518| GO:0043119 & Positive regulation of biological process & 0.000066 \\
GO:0019220 & Regulation of phosphate metabolic process & 0.000087 \\
GO:0043408 & Regulation of MAPK cascade & 0.000087 \\
GO:0051239 & Regulation of multicellular organismal process & 0.000087 \\
\hline
\end{tabular}

GO, gene ontology; FasL, Fas ligand; RA, rheumatoid arthritis.

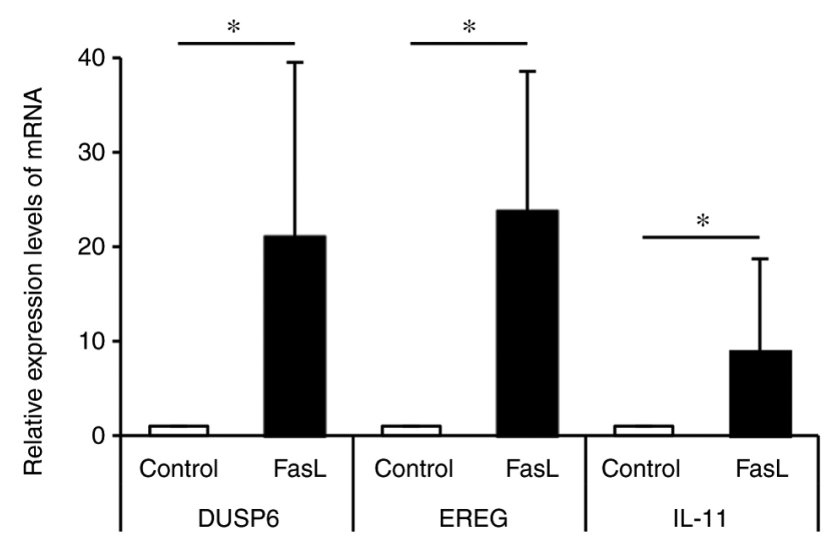

Figure 2. mRNA expression levels of the 3 most upregulated genes by FasL in RA-FLS. RT-qPCR analysis of the relative mRNA expression levels of DUSP6, EREG and IL-11 in RA-FLS after $12 \mathrm{~h}$ of incubation with $1,000 \mathrm{ng} / \mathrm{ml}$ of FasL or serum-free medium as a control is shown ( $\mathrm{n}=6$ for each gene). Control cells were assigned a value of $1 .{ }^{*} \mathrm{P}<0.05$; RT, reverse transcription; RA, rheumatoid arthritis; FLS, fibroblast-like synoviocytes; FasL, Fas ligand; DUSP6, dual specificity phosphatase 6; EREG, epiregulin.

formation mediated through IL-11R $\alpha$ ligation. Vascular endothelial growth factor and IL-8 produced from IL-11-treated RA-FLS contribute to the indirect effect of IL-11 on angiogenesis (49). In addition, IL-11 plays a key role in osteoclast formation via the gp130/Jak signaling pathway (50).

ANGPTL7 is a member of angiopoietin family that exerts pro-angiogenic activities on endothelial cells. ANGPTL7 expression has been identified in some cancer cells induced by hypoxia (51). ANGPTL7 induces proinflammatory responses in macrophages, including the induction of immune gene expression, the promotion of proinflammatory cytokine secretion, enhanced phagocytosis, and antagonized anti-inflammatory signaling through the P38 MAPK signaling pathway (52). Down-regulation of a positive regulator of inflammation might have a negative effect for inflammation in patients with RA.

PIAS proteins inhibit activated STAT and play important roles in regulating many important cellular events, such as

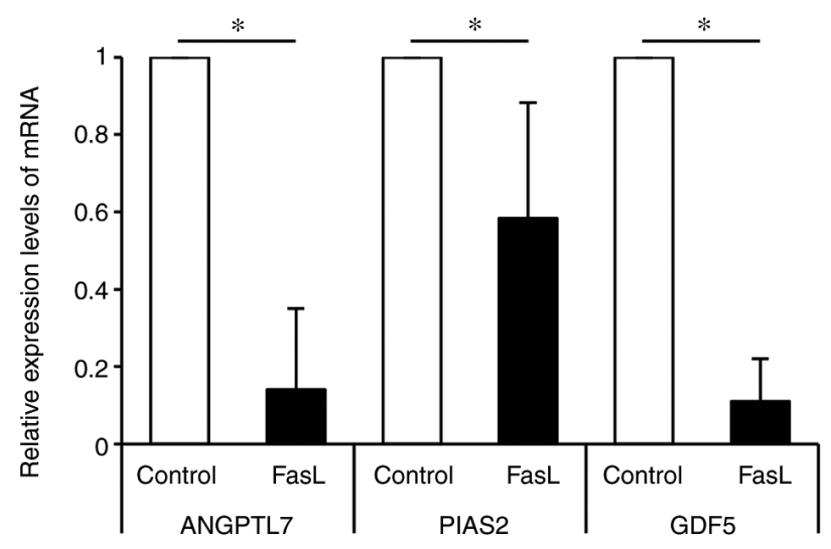

Figure 3. mRNA expression levels of the 3 most downregulated genes by FasL in RA-FLS. RT-qPCR analysis of the relative mRNA expression levels of ANGPTL7, PIAS2 and GDF5 in RA-FLS after $12 \mathrm{~h}$ of incubation with $1,000 \mathrm{ng} / \mathrm{ml}$ of FasL or serum-free medium as a control is shown ( $\mathrm{n}=6$ for each of genes). Control cells were assigned a value of 1 . ${ }^{*} \mathrm{P}<0.05$; RT, reverse transcription; RA, rheumatoid arthritis; FLS, fibroblast-like synoviocytes; FasL, Fas ligand; ANGPTL7, angiopoietin-like 7; PIAS2, protein inhibitor of activated STAT 2; GDF5, growth differentiation factor 5.

cell survival, migration, and signal transduction in many cell types $(53,54)$. PIAS proteins also modulate the activity of several transcription factors and act as E3 ubiquitin ligases in the sumoylation pathway (54-57). In a similar fashion, down-regulation of a negative regulator of inflammation might have a positive effect for inflammation in patients with RA. Lao et al reported that PIAS3 regulates migration and invasion through the Rac1/PAK1/JNK pathway in RA-FLSs (53).

GDF5 is a member of the TGF- $\beta$ superfamily and is most closely related to the bone morphogenetic protein subfamily. GDF5 increases glycosaminoglycan synthesis (58) and cartilage and bone formation (59). GDF5 is present in the synovium membrane and cartilage of patients with RA and is actively involved in the regulation of cartilage maintenance and repair (60). GDF5 is associated with joint destruction in patients with osteoarthritis (61) and RA (62). GDF5 in RA-FLS was 
suppressed by IL-1 $\beta$ and had a strong chondrogenic-promoting effect on TGF- $\beta 3$-induced chondrocyte differentiation in RA-FLS (60).

In the present study, at the first brush, we exhaustively investigated and revealed the gene expression profiles regulated by FasL in RA-FLS by the microarray assay. Secondly, we confirmed the universality of the gene expression pattern by a different method, RT-qPCR assay, using the different samples of RA-FLS from those used for the microarray assay. In order to obtain the pathological homogeneity among the samples as much as possible, the patients who underwent similar clinical features were recruited; who had been treated only with conventional DMARDs, not with biological DMARDs or targeted synthetic DMARDs, and who had their knee joint destructed severely resulting total knee replacement surgery. Therefore, we considered that there were no differences among the 10 samples. The samples 1-4 used for the microarray and 5-10 for the RT-qPCR assay were randomly selected.

The expression profiles of genes regulated by TL1A were elucidated by use of a microarray assay in our previous report (26). TL1A and FasL are bound and inhibited by the common decoy receptor, DcR3. Therefore, clarifying the relationship between the expression profiles of genes regulated by FasL and those regulated by TL1A might help us to better understand the role of the FasL/TL1A/DcR3 signaling system in the pathogenesis of RA. Further study is needed to reveal the relationship between these gene expression profiles.

The limitations of the current study include its small sample size and that it presents gene expression data only. The results of the current study revealed a series of genes whose expression is regulated by FasL in RA-FLS with microarray analysis, and the mRNA expression of some genes of note was confirmed by RT-qPCR assay. However, in addition to the expression analysis of each gene, how the genes regulated by FasL in RA-FLS are involved in the pathogenesis of RA also requires further investigation. In the current study, we aimed to analyze exhaustively the gene expression pattern regulated by FasL in RA-FLS. Therefore, the assay for expression of proteins coded by each gene should also be performed in the further studies.

In conclusion, the current study is the first, to the best of our knowledge, to report the expression profile of genes in RA-FLS regulated by FasL. These data demonstrate that FasL may regulate the gene expression of various key molecules in RA-FLS, thus affecting the pathogenesis of RA, including apoptosis, proliferation, cytokine production, cytokine-induced inflammation, intracellular signaling, angiogenesis, bone destruction, and chondrogenesis. FasL may have pleiotropic actions not only protectively but also detrimentally for RA. Further investigation of the genes detected in this profile may provide a deeper understanding of the pathogenesis of RA and new targets for its treatment.

\section{Acknowledgements}

The authors would like to thank Ms. Kyoko Tanaka, Ms. Minako Nagata, and Ms. Maya Yasuda (all from Department of Orthopaedic Surgery, Kobe University Graduate School of Medicine) for their technical assistance.

\section{Funding}

The current study was supported by Grants-in-Aid for Scientific Research (KAKENHI) (grant nos. 15K10473 and 18K09106).

\section{Availability of data and materials}

The datasets generated and analyzed during the current study are available in the NCBI's Gene Expression Omnibus (GEO) repository, GEO series accession no. GSE153378 (https://www. ncbi.nlm.nih.gov/geo/query/acc.cgi?acc=GSE153378).

\section{Authors' contributions}

KF conceived and designed the current study, was involved in data collection and analysis, confirmed the authenticity of all the raw data, wrote and gave final approval of the manuscript. YM conceived and designed the current study, was involved in data collection and analysis, confirmed the authenticity of all the raw data and gave final approval of the manuscript. TosM and TomM collected the data and gave final approval of the manuscript. SH conceived and designed the current study, was involved in data collection and analysis and gave final approval of the manuscript. RK conceived and designed the current study and gave final approval of the manuscript. All authors read and approved the final manuscript.

\section{Ethics approval and consent to participate}

The present study was approved by the Kobe University Graduate School of Health Sciences Ethics Committee (approval no. 308). All the participants provided written informed consent to participate in the present study.

\section{Patient consent for publication}

Not applicable.

\section{Competing interests}

The authors declare that they have no competing interests.

\section{References}

1. Chou CT, Yang JS and Lee MR: Apoptosis in rheumatoid arthritis-expression of Fas, Fas-L, p53, and Bcl-2 in rheumatoid synovial tissues. J Pathol 193: 110-116, 2001.

2. Tak PP, Zvaifler NJ, Green DR and Firestein GS: Rheumatoid arthritis and p53: How oxidative stress might alter the course of inflammatory diseases. Immunol Today 21: 78-82, 2000.

3. Yamanishi Y, Boyle DL, Rosengren S, Green DR, Zvaifler NJ and Firestein GS: Regional analysis of p53 mutations in rheumatoid arthritis synovium. Proc Natl Acad Sci USA 99: 10025-10030, 2002.

4. Bustamante MF, Garcia-Carbonell R, Whisenant KD and Guma M: Fibroblast-like synoviocyte metabolism in the pathogenesis of rheumatoid arthritis. Arthritis Res Ther 19: 110, 2017.

5. Baier A, Meineckel I, Gay S and Pap T: Apoptosis in rheumatoid arthritis. Curr Opin Rheumatol 15: 274-279, 2003.

6. Takami N, Osawa K, Miura Y, Komai K, Taniguchi M, Shiraishi M, Sato K, Iguchi T, Shiozawa K, Hashiramoto A and Shiozawa S: Hypermethylated promoter region of DR3, the death receptor 3 gene, in rheumatoid arthritis synovial cells. Arthritis Rheum 54: 779-787, 2006. 
7. Peng SL: Fas (CD95)-related apoptosis and rheumatoid arthritis Rheumatology (Oxford) 45: 26-30, 2006.

8. Wakisaka S, Suzuki N, Takeba Y, Shimoyama Y, Nagafuchi H, Takeno M, Saito N, Yokoe T, Kaneko A, Asai T and Sakane T: Modulation by proinflammatory cytokines of Fas/Fas ligand-mediated apoptotic cell death of synovial cells in patients with rheumatoid arthritis (RA). Clin Exp Immunol 114: 119-128, 1998.

9. Croft M and Siegel RM: Beyond TNF: TNF superfamily cytokines as targets for the treatment of rheumatic diseases. Nat Rev Rheumatol 13: 217-233, 2017.

10. Schedel J, Gay RE, Kuenzler P, Seemayer C, Simmen B, Michel BA and Gay S: FLICE-inhibitory protein expression in synovial fibroblasts and at sites of cartilage and bone erosion in rheumatoid arthritis. Arthritis Rheum 46: 1512-1518, 2002.

11. Kobayashi T, Okamoto K, Kobata T, Hasunuma T, Kato T, Hamada $\mathrm{H}$ and Nishioka K: Differential regulation of Fas-mediated apoptosis of rheumatoid synoviocytes by tumor necrosis factor alpha and basic fibroblast growth factor is associated with the expression of apoptosis-related molecules. Arthritis Rheum 43: 1106-1114, 2000

12. Scaffidi C, Fulda S, Srinivasan A, Friesen C, Li F, Tomaselli KJ, Debatin KM, Krammer PH and Peter ME: Two CD95 (APO-1/Fas) signaling pathways. EMBO J 17: 1675-1687, 1998.

13. Audo R, Calmon-Hamaty F, Papon L, Combe B, Morel J and Hahne M: Distinct effects of soluble and membrane-bound fas ligand on fibroblast-like synoviocytes from rheumatoid arthritis patients. Arthritis Rheumatol 66: 3289-3299, 2014.

14. Guegan JP and Legembre P: Nonapoptotic functions of Fas/CD95 in the immune response. FEBS J 285: 809-827, 2018.

15. Shi G, Wu Y, Zhang J and Wu J: Death decoy receptor TR6/DcR3 inhibits $\mathrm{T}$ cell chemotaxis in vitro and in vivo. J Immunol 171: 3407-3414, 2003.

16. Pitti RM, Marsters SA, Lawrence DA, Roy M, Kischkel FC, Dowd P, Huang A, Donahue CJ, Sherwood SW, Baldwin DT, et al: Genomic amplification of a decoy receptor for Fas ligand in lung and colon cancer. Nature 396: 699-703, 1998

17. Tsuji S, Hosotani R, Yonehara S, Masui T, Tulachan SS, Nakajima S, Kobayashi H, Koizumi M, Toyoda E, Ito D, et al: Endogenous decoy receptor 3 blocks the growth inhibition signals mediated by Fas ligand in human pancreatic adenocarcinoma. Int J Cancer 106: 17-25, 2003.

18. Yu KY, Kwon B, Ni J, Zhai Y, Ebner R and Kwon BS: A newly identified member of tumor necrosis factor receptor superfamily (TR6) suppresses LIGHT-mediated apoptosis. J Biol Chem 274 13733-13736, 1999.

19. Migone TS, Zhang J, Luo X, Zhuang L, Chen C, Hu B, Hong JS Perry JW, Chen SF, Zhou JX, et al: TL1A is a TNF-like ligand for DR3 and TR6/DcR3 and functions as a T cell costimulator. Immunity 16: 479-492, 2002.

20. Hayashi S, Miura Y, Nishiyama T, Mitani M, Tateishi K, Sakai Y, Hashiramoto A, Kurosaka M, Shiozawa S and Doita M: Decoy receptor 3 expressed in rheumatoid synovial fibroblasts protects the cells against Fas-induced apoptosis. Arthritis Rheum 56: $1067-1075,2007$.

21. Takahashi M, Miura Y, Hayashi S, Tateishi K, Fukuda K and Kurosaka M: DcR3-TL1A signalling inhibits cytokine-induced proliferation of rheumatoid synovial fibroblasts. Int J Mol Med 28: 423-427, 2011.

22. Fukuda K, Miura Y, Maeda T, Hayashi S and Kurosaka M: Interleukin12B is upregulated by decoy receptor 3 in rheumatoid synovial fibroblasts. Mol Med Rep 13: 3647-3652, 2016.

23. Fukuda K, Miura Y, Maeda T, Hayashi S and Kuroda R: Decoy receptor 3 down-regulates centrosomal protein $70 \mathrm{kDa}$ specifically in rheumatoid synovial fibroblasts. Mod Rheumatol 28: 287-292, 2018.

24. Maeda T, Miura Y, Fukuda K, Hayashi S and Kurosaka M: Decoy receptor 3 regulates the expression of tryptophan hydroxylase 1 in rheumatoid synovial fibroblasts. Mol Med Rep 12: 5191-5196, 2015.

25. Fukuda K, Miura Y, Maeda T, Takahashi M, Hayashi S and Kurosaka M: Decoy receptor 3 regulates the expression of various genes in rheumatoid arthritis synovial fibroblasts. Int J Mol Med 32: 910-916, 2013.

26. Fukuda K, Miura Y, Maeda T, Hayashi S and Kuroda R: Expression profiling of genes in rheumatoid fibroblast-like synoviocytes regulated by tumor necrosis factor-like ligand $1 \mathrm{~A}$ using cDNA microarray analysis. Biomed Rep 1: 1-5, 2019.
27. Arnett FC, Edworthy SM, Bloch DA, McShane DJ, Fries JF Cooper NS, Healey LA, Kaplan SR, Liang MH, Luthra HS, et al: The American Rheumatism Association 1987 revised criteria for the classification of rheumatoid arthritis. Arthritis Rheum 31: 315-324, 1988.

28. Chang Q, Peter ME and Grassi MA: Fas ligand-Fas signaling participates in light-induced apoptotic death in photoreceptor cells. Invest Ophthalmol Vis Sci 53: 3703-3716, 2012.

29. Nitobe J, Yamaguchi S, Okuyama M, Nozaki N, Sata M, Miyamoto T, Takeishi Y, Kubota I and Tomoike H: Reactive oxygen species regulate FLICE inhibitory protein (FLIP) and susceptibility to Fas-mediated apoptosis in cardiac myocytes. Cardiovasc Res 57: 119-128, 2003.

30. Thiel CT, Kraus C, Rauch A, Ekici AB, Rautenstrauss B and Reis A: A new quantitative PCR multiplex assay for rapid analysis of chromosome 17p11.2-12 duplications and deletions leading to HMSN/HNPP. Eur J Hum Genet 11: 170-178, 2003.

31. Choi YJ and Yun HK: Transcriptional profiles of Rhizobium vitis-inoculated and salicylic acid-treated 'Tamnara' grapevines based on microarray analysis. J Plant Biotechnol 43: 37-48, 2016.

32. Chang YC, Chen TC, Lee CT, Yang CY, Wang HW, Wang CC and Hsieh SL: Epigenetic control of MHC class II expression in tumor-associated macrophages by decoy receptor 3. Blood 111: 5054-5063, 2008.

33. Espinosa I, Catasus L, Canet B, D'Angelo E, Munoz J and Prat J: Gene expression analysis identifies two groups of ovarian high-grade serous carcinomas with different prognosis. Mod Pathol 24: 846-854, 2011.

34. Khan J, Simon R, Bittner M, Chen Y, Leighton SB, Pohida T, Smith PD, Jiang Y, Gooden GC, Trent JM, et al: Gene expression profiling of alveolar rhabdomyosarcoma with cDNA microarrays. Cancer Res 58: 5009-5013, 1998.

35. Whitney LW, Becker KG, Tresser NJ, Caballero-Ramos CI, Munson PJ, Prabhu VV, Trent JM, McFarland HF and Biddison WE: Analysis of gene expression in mutiple sclerosis lesions using cDNA microarrays. Ann Neurol 46: 425-428, 1999.

36. Li J, Yang S, Lu S, Zhao H, Feng J, Li W, Ma F, Ren Q, Liu B, Zhang L, et al: Differential gene expression profile associated with the abnormality of bone marrow mesenchymal stem cells in aplastic anemia. PLoS One 7: e47764, 2012.

37. van der Pouw Kraan TC, van Gaalen FA, Kasperkovitz PV, Verbeet NL, Smeets TJ, Kraan MC, Fero M, Tak PP, Huizinga TW, Pieterman E, et al: Rheumatoid arthritis is a heterogeneous disease: Evidence for differences in the activation of the STAT-1 pathway between rheumatoid tissues. Arthritis Rheum 48: 2132-2145, 2003.

38. Lee SK, Jeon EK, Kim YJ, Seo SH, Kim CD, Lim JS and Lee JH: A global gene expression analysis of the peripheral blood mononuclear cells reveals the gene expression signature in psoriasis. Ann Dermatol 21: 237-242, 2009.

39. Heller RA, Schena M, Chai A, Shalon D, Bedilion T, Gilmore J, Woolley DE and Davis RW: Discovery and analysis of inflammatory disease-related genes using cDNA microarrays. Proc Natl Acad Sci USA 94: 2150-2155, 1997.

40. Bertin S, Lozano-Ruiz B, Bachiller V, Garcia-Martinez I, Herdman S, Zapater P, Frances R, Such J, Lee J, Raz E and González-Navajas JM: Dual-specificity phosphatase 6 regulates CD4+ T-cell functions and restrains spontaneous colitis in IL-10-deficient mice. Mucosal Immunol 8: 505-515, 2015.

41. Hsu SF, Lee YB, Lee YC, Chung AL, Apaya MK, Shyur LF, Cheng CF, Ho FM and Meng TC: Dual specificity phosphatase DUSP6 promotes endothelial inflammation through inducible expression of ICAM-1. FEBS J 285: 1593-1610, 2018.

42. Patel RD, Kim DJ, Peters JM and Perdew GH: The aryl hydrocarbon receptor directly regulates expression of the potent mitogen epiregulin. Toxicol Sci 89: 75-82, 2006

43. Murakami M, Harada M, Kamimura D, Ogura H, Okuyama Y, Kumai N, Okuyama A, Singh R, Jiang JJ, Atsumi T, et al: Disease-association analysis of an inflammation-related feedback loop. Cell Rep 3: 946-959, 2013.

44. Harada M, Kamimura D, Arima Y, Kohsaka H, Nakatsuji Y, Nishida M, Atsumi T, Meng J, Bando H, Singh R, et al: Temporal expression of growth factors triggered by epiregulin regulates inflammation development. J Immunol 194: 1039-1046, 2015.

45. Lahoti TS, Hughes JM, Kusnadi A, John K, Zhu B, Murray IA, Gowda K, Peters JM, Amin SG and Perdew GH: Aryl hydrocarbon receptor antagonism attenuates grow th factor expression, proliferation, and migration in fibroblast-like synoviocytes from patients with rheumatoid arthritis. J Pharmacol Exp Ther 348: 236-245, 2014. 
46. Yin T, Taga T, Tsang ML, Yasukawa $\mathrm{K}$, Kishimoto $\mathrm{T}$ and Yang YC: Involvement of IL-6 signal transducer gp130 in IL-11-mediated signal transduction. J Immunol 151: 2555-2561, 1993.

47. Trepicchio WL, Bozza M, Pedneault G and Dorner AJ: Recombinant human IL-11 attenuates the inflammatory response through down-regulation of proinflammatory cytokine release and nitric oxide production. J Immunol 157: 3627-3634, 1996.

48. Hermann JA, Hall MA, Maini RN, Feldmann M and Brennan FM: Important immunoregulatory role of interleukin-11 in the inflammatory process in rheumatoid arthritis. Arthritis Rheum 41: 1388-1397, 1998.

49. Elshabrawy HA, Volin MV, Essani AB, Chen Z, McInnes IB, Van Raemdonck K, Palasiewicz K, Arami S, Gonzalez M, Ashour HM, et al: IL-11 facilitates a novel connection between RA joint fibroblasts and endothelial cells. Angiogenesis 21: 215-228, 2018.

50. Murakami K, Kobayashi Y, Uehara S, Suzuki T, Koide M, Yamashita T, Nakamura M, Takahashi N, Kato H, Udagawa N and Nakamura Y: A Jak1/2 inhibitor, baricitinib, inhibits osteoclastogenesis by suppressing RANKL expression in osteoblasts in vitro. PLoS One 12: e0181126, 2017.

51. Parri M, Pietrovito L, Grandi A, Campagnoli S, De Camilli E, Bianchini F, Marchio S, Bussolino F, Jin B, Sarmientos P, et al: Angiopoietin-like 7, a novel pro-angiogenetic factor over-expressed in cancer. Angiogenesis 17: 881-896, 2014.

52. Qian T, Wang K, Cui J, He Y and Yang Z: Angiopoietin-Like Protein 7 promotes an inflammatory phenotype in RAW264.7 macrophages through the P38 MAPK signaling pathway. Inflammation 39: 974-985, 2016.

53. Lao M, Shi M, Zou Y, Huang M, Ye Y, Qiu Q, Xiao Y, Zeng S, Liang L, Yang X and Xu H: Protein inhibitor of activated STAT3 regulates migration, invasion, and activation of Fibroblast-like synoviocytes in rheumatoid arthritis. J Immunol 196: 596-606, 2016.

54. Muller S, Ledl A and Schmidt D: SUMO: A regulator of gene expression and genome integrity. Oncogene 23: 1998-2008, 2004.

55. Schmidt D and Muller S: PIAS/SUMO: New partners in transcriptional regulation. Cell Mol Life Sci 60: 2561-2574, 2003.
56. Wu Y, Guo Z, Wu H, Wang X, Yang L, Shi X, Du J, Tang B, Li W, Yang L and Zhang Y: SUMOylation represses Nanog expression via modulating transcription factors Oct4 and Sox 2. PLoS One 7: e39606, 2012.

57. Chowdhury D, Singh A, Gupta A, Tulsawani R, Meena RC and Chakrabarti A: p38 MAPK pathway-dependent SUMOylation of Elk-1 and phosphorylation of PIAS2 correlate with the downregulation of Elk-1 activity in heat-stressed HeLa cells. Cell Stress Chaperones 24: 393-407, 2019.

58. Bobacz K, Gruber R, Soleiman A, Graninger WB, Luyten FP and Erlacher L: Cartilage-derived morphogenetic protein-1 and -2 are endogenously expressed in healthy and osteoarthritic human articular chondrocytes and stimulate matrix synthesis. Osteoarthritis Cartilage 10: 394-401, 2002.

59. Hotten GC, Matsumoto T, Kimura M, Bechtold RF, Kron R, Ohara T, Tanaka H, Satoh Y, Okazaki M, Shirai T, et al: Recombinant human growth/differentiation factor 5 stimulates mesenchyme aggregation and chondrogenesis responsible for the skeletal development of limbs. Growth Factors 13: 65-74, 1996.

60. Liu FL, Lin LH, Sytwu HK and Chang DM: GDF-5 is suppressed by IL-1beta and enhances TGF-beta3-mediated chondrogenic differentiation in human rheumatoid fibroblast-like synoviocytes. Exp Mol Pathol 88: 163-170, 2010

61. Miyamoto Y, Mabuchi A, Shi D, Kubo T, Takatori Y, Saito S, Fujioka M, Sudo A, Uchida A, Yamamoto S, et al: A functional polymorphism in the 5' UTR of GDF5 is associated with susceptibility to osteoarthritis. Nat Genet 39: 529-533, 2007.

62. Martinez A, Varade J, Lamas JR, Fernandez-Arquero M, Jover JA de la Concha EG, Fernandez-Gutierrez B and Urcelay E: GDF5 Polymorphism associated with osteoarthritis: Risk for rheumatoid arthritis. Ann Rheum Dis 67: 1352-1353, 2008. International (CC BY-NC-ND 4.0) License. 